\title{
Mental Illness Recognition and Referral Practices Among Imams in the United States
}

\author{
Osman M. Ali, M.D.
}

The University of Texas Southwestern Medical Center

Glen Milstein, Ph.D.

The City College of the City University of New York

\section{Abstract}

Imams are Muslim clergy whose community members rely on them for help with life stresses, and therefore play a significant role in addressing the counseling needs of the growing Muslim communities in the United States. We studied if imams could recognize mental illness and would be willing to make referrals. We mailed a questionnaire to a nationwide sample of imams. The survey included a vignette depicting a congregant exhibiting signs of depression. The survey elicited answers to questions about the etiology of the presenting problem, as well as recommendations for referrals to meet the congregant's needs. Imams recognized that the congregant's problem would not resolve without intervention. They expressed a broad range of attitudes toward etiology as well as helpful interventions. Although some imams reported that they would be willing to collaborate with mental health professionals, they reported infrequent consultation practices in their communities. The amount of the imams' previous consultation experience was correlated with greater willingness to collaborate in response to the vignette $(p<.05)$, as well as recognition of the utility of psychiatric medication ( $p<.05)$. Imams' own counseling training was correlated with less willingness to collaborate $(p<.05)$. In order to minimize disparities of mental health care for the growing Muslim population in the United States, a focus on imam collaboration and reciprocal consultation, including clinical pastoral training, would help Muslim communities to utilize clinical resources, and help clinicians to provide more culturally competent care. The traditional role of an imam is to lead prayers, 
deliver sermons, and conduct religious ceremonies, as well as to provide counsel to individuals and their families. Outside of the United States, imams even help resolve disputes that in the United States would be reserved for legal courts (Al-Issa, 2000; S. R. Ali, Liu, \& Humedian, 2004). Therefore, in times of duress, Muslim communities call on their imam to reference and interpret their scriptures (Qur'an and Hadith) in order to ameliorate their distress. Imams are de facto mental health care providers.

Muslims in the United States are a minority group who face increasing religious, cultural, and ethnic discrimination (Ali, Milstein, \& Marzuk, 2005). Although these stressors place them at risk for mental health problems (AlIssa, 1997; Geronimus, Hicken, Keene, \& Bound, 2006; McEwen, Lasley, Monat, Lazarus, \& Reevy, 2007), Muslims have disparately low utilization of mental health services. In the United States, imams actively counsel members of their congregation across a wide range of problems (Ali et al., 2005). Yet, some serious mental health needs require clinical intervention beyond the scope of clergy counseling (Milstein, Manierre, Susman, \& Bruce, 2008; Milstein, Manierre, \& Yali, 2010). Frequently, clergy make insufficient use of mental health professionals to relieve the burden of responding to serious mental disorders (Wang, Berglund, \& Kessler, 2003).

We hypothesize that Muslim may infreqently receive mental health care due to the lack of referrals from many imams who were not born in the United States and therefore are unfamiliar with widely used diagnostic categories for mental illness. As with other clergy across many religious traditions, imams also may not distinguish between mental and spiritual problems, and therefore see the burden of care for their congregant resting on themselves alone (McMinn \& Dominguez, 2005; Milstein et al., 2008).

Although there is historic compatibility between Islam and medicine (Morgan, 2007), there remains stigma toward mental illness (Al-Issa, 2000). Therefore, even if imams do recognize that the seriousness of a person's emotional distress is outside of their own expertise, they may be unwilling to make a referral or consult with a clinician. Another reason why imams may not collaborate with clinicians - which they share with clergy from other faiths-is the view that the clinician may not be sensitive to the religious values of their congregants or may hold views of religion antithetical to their own (Bobgan \& Bobgan, 1987; Vitz, 1994). A specific reason why imams may be unwilling to collaborate with clinicians is concern about discrimination because of their religion (Ali et al., 2005). In order for clergy to facilitate their congregants' access to professional clinical care, they must first recognize the need for a referral, they must then be willing to refer, and they need to have a network of professionals to whom they can refer (Milstein et al., 2008).

The purpose of this paper is to investigate three questions: 
1. Could imams recognize the severity of a mental health problem?

2. Would imams be willing to refer a person with symptoms of a serious mental disorder to a clinician?

3. Do age, consultation experience, or counseling training correlate with collaboration between imams and mental health professionals?

\section{Methods}

We conducted a cross-sectional, self-report survey of imams from mosques throughout the United States in 2003, which was approved by our institutional research review board. Sixty-two (male) imams returned the survey. The questionnaire, survey methodology, and response rates were described in a previous article (Ali et al., 2005). We examined the imams' recognition of a mental health problem, their opinions about the appropriate type of referral, and then correlated these responses with age, consultation experience, and counseling training.

To calculate the imams' consultation experience, they were asked to describe the frequency of six types of interaction in the past year. The imams responded to a four-point Likert scale representing contact frequency: Never = 1; One to Five $=2$; Six to Ten $=3$; More than Ten $=4$. A total score for contact with professionals was calculated for each participant, with a possible range of 6 to 24. The wording of the question, the list of the six categories, and the percentage of imams who had any contact is found in Table 1, section A.

To calculate the imams' level of training, they were asked to respond to a list of training experiences. The participants were asked to circle all the answers that applied to them. Each answer that the participant circled received one point, with a total possible range of 0 to 7 . The wording of the question, the list of the seven types of training, and the percentage of imams who had any training experience is found in Table 1 , section B.

In order to study the imams' recognition of a mental health problem, as well as their opinions about the appropriate type of referral, imams read the following vignette-adapted from previous studies (Link, Phelan, Bresnahan, Stueve, \& Pescosolido, 1999; Milstein, Midlarsky, Link, Raue, \& Bruce, 2000; Weaver, 1993)—that depicts a person exhibiting signs of depression and with possible risk for suicide:

With strong encouragement from his friends, Mr. Ahmed who is 62 years old, comes to speak to you after Friday Prayer. He looks very sad and disheveled. It has been two years since his wife's death. Over the past year, 
he has stopped spending time with his friends. He tells you that although he feels very tired, he is unable to sleep at night. He then says, 'I can't see anything worth living for-life feels pointless without her.'

The imams were asked four questions in response to the vignette (Table 2). For each question, the imams were asked to rate multiple answers with a four-point Likert scale. There were a total of 25 responses. For each response we calculated means, standards deviations, and Pearson-Rho values of the correlation of the response with the imams' age, consultation experience, and counseling training (Table 2).

At the end of the questionnaire we invited imams to make additional comments to describe their experience with consultation.

\section{Results}

The imams' ages ranged from 24 to 69 with a mean of $49(S D=12)$. We identified a great variation in consultation experience among imams. For each category of consultation experience (Table 1, A) there was at least one imam who reported consultation with a provider more than ten times. Yet overall, $20 \%$ of the imams had made no contact in the past year with any of the six types of clinical consultants. Over half of the imams reported contact with a primary

TABLE 1. The Percentage of Imams Who Have Sought Consultation or Received Counseling Training

\begin{tabular}{lcc}
\hline $\begin{array}{l}\text { A. How many times have you consulted with } \\
\text { or referred to each of the following in the past } \\
\text { year, for any of your congregants? }\end{array}$ & $N$ & $\begin{array}{c}\text { \% with any } \\
\text { Consultation }\end{array}$ \\
\hline 1. Family Doctor or Primary Care Doctor & 48 & 60 \\
2. Social Worker or Marriage/Family Counselor & 51 & 57 \\
3. Imam familiar with Psychotherapy & 52 & 46 \\
4. Psychiatrist or Psychologist & 50 & 46 \\
5. Community Mental Health Center & 50 & 26 \\
6. Psychiatric Hospital or Emergency Room & 48 & 15 \\
& & $\%$ with any \\
B. Have you had any of the following experiences? & & Training \\
\hline 1. College Psychology Courses & 56 & 45 \\
2. Personal Reading in Counseling & 56 & 43 \\
3. Courses in Psychology at an Islamic School & 56 & 32 \\
4. Other Training or Counseling Experiences & 56 & 25 \\
5. Consultation or Supervision with a Mental & 56 & 25 \\
$\quad$ Health Professional & & \\
6. Counseling Classes from an Islamic organization & 56 & 21 \\
7. Clinical Pastoral Training & 56 & 12 \\
\hline
\end{tabular}


care physician or social worker, and nearly half of the imams contacted an imam familiar with mental health issues, or a psychiatrist or psychologist in the past year. Far fewer imams referred congregants to community mental health clinics or psychiatric hospitals.

For counseling training (Table 1, B) there was also variation with overall low participation. While $7 \%$ of the imams reported experience with five of the seven categories of training, and $14 \%$ with four categories; $18 \%$ of the imams reported no type of training, and $27 \%$ had only one type of training. Less than half the imams reported receiving any training. Some reported college courses and individual reading, and some took psychology courses in their religious education. The least experience for the imams was in clinical pastoral training.

The data in Table 2 describe the imams' responses to the vignette of Mr. Ahmed, a person exhibiting signs of depression with possible risk for suicide. In the first question (Table 2, A), the imams responded to the likelihood that Mr. Ahmed's problem was attributable to each of seven etiologies. They attributed the cause most strongly to stress and least strongly to a genetic problem. They then attributed it to both a religious problem and a weak personality. They were less likely to attribute it to brain chemistry or being physically sick. There was a significant positive correlation between the imams' age and attributing the problem to how Mr. Ahmed was raised, as well as to a weak personality.

In the second question (Table 2, B) the imams evaluated the helpfulness of seven types of interventions. Three of their top four answers were religionbased. The imams most strongly recommended more participation at the mosque. While this was followed by a nonreligious therapeutic dialogue to clarify Mr. Ahmed's thinking and feeling, that score was statistically indistinguishable from reading religious texts and praying. The helpfulness of all talk interventions were affirmed more strongly than the helpfulness of psychiatric medication. Overall, the imams evaluated psychiatric medication as the least helpful intervention. Consultation experience by imams was positively correlated with recognition of the helpfulness of both psychiatric medication and mosque participation.

In the third question (Table 2, C), the imams were asked the probability that they would do each of six types of consultation in response to Mr. Ahmed. On average, the imams rejected the idea that his problem would improve without help. They expected to consult with another imam familiar with psychotherapy, and this consultation was correlated with overall consultation experience. They also reported that they would likely counsel Mr. Ahmed themselves. This outcome was positively correlated with both their consultation experience as well as their own counseling training. On average, imams also expected that they would refer Mr. Ahmed to a mental health professional while continuing to counsel him themselves. The imams were less inclined to seek counsel from 
TABLE 2. Four questions and the Imams mean scores in response to the vignette of a person exhibiting signs of depression with possible risk for suicide

A. "In your opinion, how likely is it that Mr. Ahmed's situation might be caused by each of the following"a

1. Stressful circumstances in his life

\begin{tabular}{ccc}
$N$ & Mean & SD \\
\hline 55 & 3.42 & 0.81 \\
52 & 2.79 & 0.96 \\
51 & 2.75 & 0.77 \\
48 & 2.48 & 0.90 \\
51 & 2.47 & 1.01 \\
50 & 2.16 & 1.00 \\
50 & 1.80 & 0.81
\end{tabular}

2. A religious or spiritual problem

B. "How helpful do you think each of the following might be for Mr. Ahmed," a

1. Recommend more active participation at mosque $d$

2. Clarify thinking and feeling

$\begin{array}{lll}53 & 3.66 & .55\end{array}$

3. Read Qur'an and Hadith with congregant

$3.53 \quad .64$

4. Pray with congregant

5. Explore past and present experiences

$3.48 \quad .67$

6. Discuss marital/family relationships

$3.19 \quad .83$

7. Psychiatric medication ${ }^{d}$

$2.98 \quad .84$

$\begin{array}{lll}50 & 2.64 \quad .90\end{array}$

C. "To what degree do you think you would do each of the following if

Mr. Ahmed were to come to you for help," b

1. Imam would consult or refer to another imam familiar with psychotherapy ${ }^{d}$

$\begin{array}{lll}49 & 3.24 & .85\end{array}$

2. Imam would counsel congregant themselves ${ }^{d, e}$

3. Imam would refer to a MHP and continue seeing themselves

4. Imam would consult a MHP for advice

$\begin{array}{lll}50 & 3.04 & .88\end{array}$

5. Imam would refer to a Mental Health Professional

$\begin{array}{lll}51 & 2.78 & .92\end{array}$

6. Improve without help

$\begin{array}{lll}51 & 2.69 & .84\end{array}$

$\begin{array}{lll}55 & 1.87 & .94\end{array}$

D. "To what degree do you think a psychiatrist, psychologist or social worker should do each of the following if Mr. Ahmed were to come to them for help ${ }^{b}$

1. MHP should consult other MHP familiar with religious issues $\begin{array}{llll}52 & 3.50 & .61\end{array}$

2. MHP should consult clergy for advice

$\begin{array}{lll}50 & 3.32 & .77\end{array}$

3. MHP should refer to clergy and continue seeing themselves ${ }^{d}$

4. MHP should refer to clergy ${ }^{\mathrm{e}}$

$\begin{array}{lll}52 & 3.12 & .83\end{array}$

5. MHP should counsel person themselves

$50 \quad 2.76 \quad .98$

Likert Values of Answers: Significant Correlations $(P<.05)$ :

$\begin{array}{ll}{ }^{\mathrm{a}} 1=\text { Not at all, } 2=\text { Not Very, } 3=\text { Somewhat, } 4=\text { Very } & { }^{\text {cAge }} \\ { }^{\mathrm{b}} 1=\text { Definitely Not, } 2=\text { Probably Not, } & { }^{\mathrm{d} C o n s u l t a t i o n ~ E x p e r i e n c e ~} \\ 3=\text { Probably, } 4=\text { Definitely } & { }^{\mathrm{e} C} \text { Counseling Training }\end{array}$


professional mental health care providers, or refer Mr. Ahmed away to a clinician.

In the fourth question (Table 2, D), the imams were asked the relative importance of each of five actions that a mental health professional should do to help Mr. Ahmed. The imams felt that it was important for the clinician to become familiar with Mr. Ahmed's religious issues. They most strongly indicated that mental health professionals could get this knowledge from a fellow clinician. They then thought that the clinicians could seek consultation or collaboration with clergy. This option to seek collaboration (Table 2, D, 3) was positively correlated with the imams' own consultation experience. The imams affirmed that the clinician should refer Mr. Ahmed to an imam; they were least inclined to think that the clinician should counsel Mr. Ahmed alone. The opinion that Mr. Ahmed should be referred to an imam was correlated with clergy counseling training.

A number of narrative comments are noteworthy. Some imams reminded the researchers that we were "sending this to an imam that has knowledge in Islam and that seeks to solve all problems through Islam (Quran/Hadith). We have degrees in religion and not in science." Others appreciated that although Islam can have a "spiritual and psychological impact," there were some imams who "were not helping in the most effective way." They recognized a need for "psychological assistance," and expressed a desire for "psychologists, psychiatrists, and social workers" to support them in addressing issues of their congregants.

In other narrative comments many imams reported that they were volunteers, or did not have enough time to provide for the basic mosque needs let alone all of the psychosocial needs of their community members.

Although a few reported positive interfaith events following the September $11^{\text {th }}$ attacks, most suggested that in the current environment, "psychological problems [of Muslims] will magnify even further" and suggested several reasons, including "cases of discrimination in the workplace ... and harassment" in the community; and government responses focused on "monitoring sermons" and freezing bank accounts during "investigations" making people "afraid of FBI [Federal Bureau of Investigations] or CIA [Central Intelligence Agency]." That is, "revealing problems may have a negative impact on the status of the person" and "no one pays zakat [obligatory charity] to the masjid [mosque] anymore because of 9/11."

\section{Discussion}

Our principal finding is that imams can recognize the severity of a serious mental health problem, as they acknowledged that the problem presented to 
them would not resolve without intervention. Further, we found on average that imams would be more willing to refer a congregant to a mental health professional while continuing to counsel themselves, than to refer the congregant away to receive counselling only from the mental health professional. To our knowledge, this study is the first to describe and quantify a pattern of Muslim clergy responses to a mental illness, as well as to describe factors that could influence the imams' response to this presenting problem.

The imams reported a broad range of attitudes toward mental illness in terms of etiology and helpful interventions, but few reported actually utilizing professional health care resources. Our analysis suggests that although most imams do not believe that religious interventions are mutually exclusive from mental health interventions for the treatment of mental illness, they infrequently consult with mental health professionals. The survey responses and additional comments help to elucidate possible solutions to this problem of disparity between willingness and utilization.

A polarity emerged from the data that may inform future work to improve collaboration between imams and clinicians. First, more counseling training by imams was correlated with the imams' intent to counsel their congregantMr. Ahmed-alone, as well as their expectation that a clinician should refer the man to an imam without providing clinical care, which would not be the best intervention for Mr. Ahmed. A different set of recommendations was correlated with a history of contact between mental health professionals and imams. Greater contact was correlated with greater willingness to collaborate, including greater recognition of the utility of psychiatric medication, as well as recommending more active participation in the mosque. This congruence between biological and religious interventions among imams who have had more contact with mental health professionals indicates that future interventions to encourage collaboration across professional expertise would find greater success than training imams in clinical skills alone. This is consistent with the contact hypothesis described by Corrigan (2005). This hypothesis states that organized contact with individuals different from you will more effectively change your attitudes toward their group than education alone.

One area of education with potential to improve collaboration that few imams have experienced is clinical pastoral training. This course of study provides a way to approach mental health care as part of a multidisciplinary team. The imams could learn both the potential of their expertise and the utility of the expertise of others (VandeCreek \& Lucas, 2001).

Another approach to engage the Muslim community through their imams is the prevention science model of Clergy Outreach and Professional Engagement (COPE; Milstein et al., 2008; Milstein et al., 2010). Imams, like other clergy, have a multiplicity of roles that their communities count on them to perform (Milstein et al., 2005). Yet without adequate training, resources, or 
community affiliations, the task is overburdensome. The COPE model acknowledges the scope of imams' practices in relationship to addressing their congregants' diverse needs, and describes a continuum of professional collaboration as a way to reduce the burdens of community clergy. The continuum moves from the care already present in religious communities, through professional clinical care provided in response to dysfunction, and returns persons to their own spiritual communities. COPE delineates boundaries between clinical care provided by mental health professionals and religious care provided by clergy, as well as describes pathways of collaboration across these boundaries (Milstein et al., 2010).

The imams' comments also direct clinicians to have an appreciation of the environment in which most imams practice. Imams must provide encouragement and support to congregants who may themselves be reluctant to utilize services outside of their communities because of a concern that their religious and spiritual requirements may be misunderstood or inadvertently transgressed upon. Yet there are very few Muslim mental health providers.

This study had several limitations. It was a preliminary study that sought, for the first time, to examine imams' perceptions of mental illness and the treatment pathways that they would consider to be helpful. There is much future work to do. We studied a small self-selecting sample. We offered one vignette that was adapted from previous studies and not tested before in the Muslim community. We examined correlations to begin to understand the influences on imams' perceptions of mental illness and mental health care. Future studies will look for larger samples examining multiple types of presenting problems with additional controls and multivariate analysis. Interventions to improve collaboration will be further informed by these future studies.

\section{Conclusions}

In order to minimize disparities of mental health care to the growing Muslim population in the United States, community healthcare planners need to appreciate that (a) within their communities, imams are an important source of referrals and influence on the attitudes toward mental health and help-seeking; (b) imams are able to recognize serious mental health problems; and (c) imams appear more willing to collaborate with mental health professionals if they have had previous consultation experiences. Therefore, the data would predict that interventions focused on collaboration and reciprocal consultation would be more effective than clinical training for imams. With such collaboration, Muslim communities may be more likely to utilize community resources, clinicians will be more likely to provide culturally competent care, and imams will then be more effective in their collaborative role as de facto mental health providers. 


\section{References}

Al-Issa, I. (1997). The psychology of prejudice and discrimination. In I. Al-Issa \& M. Tousignant (Eds.), Ethnicity, immigration, and psychopathology (pp. 17-32). New York: Plenum Press.

Al-Issa, I. (Ed.). (2000). Al-Junun: Mental illness in the Islamic world. Madison, CT: International Universities Press.

Ali, O. M., Milstein, G., \& Marzuk, P. M. (2005). The imam's role in meeting the counseling needs of Muslim communities in the United States. Psychiatric Services, 56, 202-205.

Ali, S. R., Liu, W. M., \& Humedian, M. (2004). Islam 101: Understanding the religion and therapy implications. Professional Psychology: Research and Practice, 35, 635642.

Bobgan, M., \& Bobgan, D. (1987). Psychoheresy: The psychological seduction of Christianity. Santa Barbara, CA: Eastgate Publishers.

Corrigan, P. W. (2005). On the stigma of mental illness: Practical strategies for research and social change. Washington, D.C.: American Psychological Association.

Geronimus, A. T., Hicken, M., Keene, D., \& Bound, J. (2006). "Weathering" and age patterns of allostatic load scores among blacks and whites in the United States. American Journal of Public Health, 96, 826-833.

Link, B. G., Phelan, J. C., Bresnahan, M., Stueve, A., \& Pescosolido, B. A. (1999). Public conceptions of mental illness: Labels, causes, dangerousness, and social distance. American Journal of Public Health, 89, 1328-1333.

McEwen, B., Lasley, E. N., Monat, A., Lazarus, R. S., \& Reevy, G. (2007). Allostatic load: When protection gives way to damage. In A. Monat, R. S. Lazarus, \& G. Reevy (Eds.), The Praeger handbook on stress and coping (vol.1). (pp. 99-109). Westport, CT: Praeger Publishers/Greenwood Publishing Group.

McMinn, M. R., \& Dominguez, A. W. (Eds.). (2005). Psychology and the church. Hauppauge, NY: Nova Science Publishers.

Milstein, G., Kennedy, G. J., Bruce, M. L., Flannelly, K. J., Chelchowski, N., \& Bone, L. (2005). The clergy's role in reducing stigma: A bilingual study of elder patients' views. World Psychiatry, 4(S1), 28-34.

Milstein, G., Manierre, A., Susman, V. L., \& Bruce, M. L. (2008). Implementation of a program to improve the continuity of mental health care through Clergy Outreach and Professional Engagement (C.O.P.E.). Professional Psychology: Research and Practice, 39, 218-228.

Milstein, G., Manierre, A., \& Yali, A. M. (2010). Psychological care for persons of diverse religions: A collaborative continuum. Professional Psychology: Research and Practice, 41, 371-381.

Milstein, G., Midlarsky, E., Link, B. G., Raue, P. J., \& Bruce, M. L. (2000). Assessing problems with religious content: A comparison of rabbis and psychologists. Journal of Nervous and Mental Disease, 188, 608-615.

Morgan, M. H. (2007). Lost history: The enduring legacy of Muslim scientists, thinkers, and artists. Washington, D.C.: National Geographic Books.

VandeCreek, L., \& Lucas, A. M. (Eds.). (2001). The discipline for pastoral care giving: Foundations for outcome oriented chaplaincy. Binghamton, NY: Haworth Press.

Vitz, P. C. (1994). Psychology as religion: The cult of self-worship. Grand Rapids, MI: Wm. B. Eerdmans. 
Wang, P. S., Berglund, P. A., \& Kessler, R. C. (2003). Patterns and correlates of contacting clergy for mental disorders in the United States. Health Services Research, 38, 647-673.

Weaver, A. J. (1993). Suicide prevention: What clergy need to know. Journal of Psychology and Christianity, 12, 70-79. 